\title{
Tackling pain after cardiac surgery: It takes a village!
}

\author{
Discussion Paper \\ Geraldine Martorella ${ }^{1}$ \\ ${ }^{1}$ College of Nursing, Florida State University, Florida, USA \\ Corresponding author: G. Martorella (gmartorella@fsu.edu)
}

\begin{abstract}
There is increasing concern regarding the risk to develop chronic pain after cardiac surgery with potential detrimental effects on recovery and quality of life. With shortened hospital stays after cardiac surgery, there needs to be more emphasis placed on self-management skills and the support provided to patients and their informal caregivers during the subacute phase. A paradigm shift needs to occur on multiple levels to prevent chronic pain and opioid misuse after surgery. Initiating this change means redefining the timing, recipients, and content and format of interventions. Several avenues can be examined and translated in practice to promote a successful transition after cardiac surgery.
\end{abstract}

\section{KEYWORDS}

Biopsychosocial model pain, Cardiac Surgery, Chronic Pain, Pain Intervention, Recovery

\section{INTRODUCTION}

Cardiac surgeries became frequent surgical procedures (Virani et al., 2021) with reduced length of stay in hospitals (Engelman et al., 2019; Son et al., 2021). However, postoperative persistent pain or chronic post-surgical pain (CPSP) after cardiac surgery, i.e. pain developing after surgery and lasting at least 3 months with other causes of pain excluded (Kehlet, 2014), has become more and more of a concern and can have a considerable impact on recovery and long term clinical outcomes (Guimaraes-Pereira et al., 2017). Of note, the relationship between chronic pain and cardiovascular disease (CVD) is currently being investigated. Several studies report a higher risk of reporting CVD if suffering from chronic pain (Bruehl et al., 2018; Fayaz et al., 2016; Oliveira et al., 2020; van Hecke et al., 2017), associations between chronic pain and mortality related to CVD, and a dose-response relationship with increasing pain severity being associated with more cardiovascular outcomes (Fayaz et al., 2016). Following discharge from the hospital, patients are exposed to a greater risk for CPSP and prolonged opioid use (Hirji et al., 2019), as they still experience high levels of pain and need to selfmanage their pain (Bjornnes et al., 2016; Guimaraes-Pereira et al., 2017). Moreover, the risk of CPSP is usually not known by patients (Oliver et al., 2016), which likely lead them to consult once the pain has already become chronic (Clarke, 2016).

Can we prevent the chronification of pain after cardiac surgery? The answer is not that simple but with the help of a biopsychosocial model pain (Gatchel et al., 2007), the most comprehensive pain framework, experts from multidisciplinary fields of research are certainly examining solutions addressing the diversity of risk factors involved in this process. Among these, psychosocial protective and risk factors have gained increased attention as they are, to a certain extent, modifiable, and highly related to pain intensity and future functioning (Edwards et al., 2016). For instance, it has been 
shown that pain cognitions, such as pain-related catastrophic thoughts, negatively influence postoperative pain intensity and activity levels, thus contributing to the development of chronic postoperative pain, as opposed to self-efficacy and optimism which would enhance recovery (Weinrib et al., 2017). Additionally, targeting these factors concurs with an increased interest for nonpharmacological interventions (HEAL initiativePain Management Effectiveness Research Network 2019; Interagency Pain Research Coordinating Committee-National Pain Strategy Overview, 2016), potentially preventing opioid overuse or misuse. For decades, non-pharmacological approaches for postoperative pain have been focusing on the use of educational interventions in the acute care setting. However, although beneficial to anxiety levels, the lack of efficacy of these interventions on pain intensity (Ziehm et al., 2017), both preoperatively and postoperatively, has been consistently reported. These findings along with advances in the understanding of the development of CPSP calls for a paradigm shift. This shift may need to occur on multiple levels: timing of interventions, recipients of these interventions, and type of interventions.

\section{TIMING OF INTERVENTIONS}

One of the most important risk factors in the development of CPSP is postoperative acute pain intensity level (Katz \& Seltzer, 2009; Schug \& Bruce, 2017). With people having shorter hospital stays after cardiac surgery (Son et al., 2021), acute pain becomes a problem to address at home during recovery. Surprisingly, a lack of studies documenting pain after discharge from hospital has been observed (Park et al., 2020), thus reflecting a gap in postoperative pain management and the need to increase our efforts in understanding the experience of postoperative pain and the potential of efficacy of interventions in this phase of the postoperative continuum. Moreover, although non-pharmacological interventions for postoperative pain are integrated in clinical practice guidelines (Chou et al., 2016), recent studies still highlight multiple barriers in implementing such interventions in the acute care setting (Martorella \& McDougall, 2021; Warren et al., 2020). Although efforts to implement these interventions in acute care settings must be pursued, it seems important to offer these in the community following discharge in order to prevent a serious setback in pain management during recovery when activity levels should be gradually increasing.

Furthermore, clinicians involved at different timepoints in the cardiac surgical care continuum tend to express the importance of developing selfmanagement support for patients after discharge (Martorella et al., 2018). Indeed, according to nurses, patients can lack self-motivation, especially if living by themselves, and compliance with treatment seems challenging once discharged from hospital. In the context of discharge planning, the traditional approach to prepare cardiac surgical patients for their recovery at home has been to educate them during hospitalization or at the time of discharge. However, interventions occurring following discharge, once patients must apply what they learned, have previously shown to be more effective than self-management education during hospitalization (Akbari \& Celik, 2015; Fredericks \& Yau, 2013), as well as preferred by patients (Lapum et al., 2016; Martorella et al., 2014). Of note, this recommendation is in line with the increasing emphasis placed on patientcentered subacute care and the prevention of readmission after cardiac surgery (Mori et al., 2019).

\section{RECIPIENTS OF INTERVENTIONS}

With a fast-tracked acute care phase, the role of informal caregivers in the management of pain is becoming more and more significant. Additionally, pain being a subjective phenomenon learned through life experiences and influenced by biological, psychological, and social factors (Raja et al., 2020), it is logical to think that the personal pain-related experiences of family members or informal caregivers will impact the patient's pain. It comes as no surprise that psychosocial risk and protective factors for CPSP also include significant others in relation to social support and solicitous responding (Katz \& Seltzer, 2009). Solicitous responding has been defined as "behaviors on the part of significant others that unwittingly positively and/or negatively reinforce the patient's pain behaviors thereby increasing their frequency of occurrence" (Katz \& Seltzer, 2009, p. 726). Thus, 
most guidelines recommend the inclusion of family members in postoperative pain management interventions (Chou et al., 2016).

Nevertheless, very few studies have examined caregiver-facilitated pain management interventions in hospitalized adults (Yasmeen et al., 2020), as well as interventions focused on support for caregivers when transitioning at home (Bjornnes et al., 2019). Hence, in a systematic review of 42 studies including caregivers of cardiac surgery patients, solely 7 intervention studies were found (Bjornnes et al., 2019). The findings reflected caregivers feel insecure and lack information and support during the recovery at home (Bjornnes et al., 2019). Yet, interventions educating caregivers and involving them in pain management seem promising in contributing to the reduction of pain intensity as well as opioid consumption (Rahmani et al., 2020; Yasmeen et al., 2020) and could even promote the use of positive pain coping strategies (Grondin et al., 2014).

\section{TYPE OF INTERVENTIONS}

Given the increasing value of the subacute phase, the importance of patients' self-management skills cannot be overstressed. In view of the lack of efficacy of educational interventions on pain management, it is legitimate to wonder if interventions' targets should be revaluated as well as their active ingredients. Moreover, pain is generally not a big concern for cardiac surgical patients (Cogan et al., 2014; Martorella et al., 2014) who express more informational needs regarding other types of postoperative complications (Veronovici et al., 2014). This perception is related to core beliefs and attitudes that cause the normalization of pain and reluctance to take any actions. Advances on the importance of psychosocial risk and protective factors for pain have emphasized the relevance of cognitive and behavioral approaches, especially after discharge, when patients are trying to return to some normalcy. Cognitive behavioral therapy (CBT) and its variations, such as acceptance commitment therapy (ACT) and mindfulness-based cognitive therapy (MBCT), are suited to influence CPSP risk and protective factors as they target painrelated cognitions and behaviors, i.e. the foundation for individual self-management skills (Weinrib et al., 2017).

Hence, we may also want to investigate the impact of tailoring the content of interventions according to the individual profile of risk and protective factors. For instance, some patients may not present pain-related catastrophic thoughts and not require cognitive restructuring. This would mean that a standard CBT approach may not be relevant for everyone. A preliminary screening of these psychosocial risk and protective factors could help determine the content of the intervention. Content matching is an important tailoring ingredient that is frequently missing, even in interventions addressing chronic pain (Martorella et al., 2017). Of note, the evaluation of these factors may need to be done several times along the continuum, e.g. before and after surgery as their predictive power may change over time or depending on the type of surgery (Weinrib et al., 2017). As an example, while pain catastrophizing may not be present preoperatively in cardiac surgical patients who are more focused on survival, it may be present postoperatively due to the pain related to their sternotomy.

\section{FORMAT OF INTERVENTIONS}

However, implementing these CBT-based interventions following discharge may present several challenges in the context of a surgical population, such as the cardiac surgical population, and may require modifying their format. Indeed, for instance, they usually require weekly group meetings for 8-12 weeks, which is rather taxing during recovery after a major surgery and not always necessary if pain is not yet chronic and disability has not surfaced. These interventions may require adaptations to better fit the recovery period following hospital discharge and the prevention of CPSP. Several studies have successfully tested brief versions of these approaches with surgical populations (McClintock et al., 2019; Weinrib et al., 2017).

Lastly, another adaptation to explore is a webbased or online format of interventions, which has previously shown benefits in the perioperative continuum of care (van der Meij et al., 2016). As an example, a mobile health or social media-based 
application accessible from smartphones and tablets seems to be a promising and convenient tool to incorporate into cardiac rehabilitation, particularly for underserved populations (Dorje et al., 2019; Liu et al., 2020). This format allows instant guidance and feedback this is patientcentered, i.e., tailored to individual needs in terms of content, timing, and dosage. Furthermore, integrating messages from a clinician creates a sense of connectedness and personalized consultation that could enhance motivation and engagement (Dorje et al., 2019; Martorella et al., 2018). Additionally, according to patient preferences, the intervention could be hybrid with the combination of a mobile application and brief check-ins with a coach by telephone. Moreover, although embryonic, the use of technologies is also emerging as a tool to facilitate accessibility to interventions including informal caregivers (Shaffer et al., 2020) and the social-media based application seems like a convenient tool to integrate caregivers.

\section{CONCLUSION}

Although providing support beyond discharge as well as involving caregivers have previously been suggested in studies and guidelines, these recommendations have not been reflected in research and practice. Today, with shortened hospital stays after cardiac surgery and the known risk of CPSP and opioid misuse, we have a responsibility to initiate change by increasing awareness regarding CPSP and providing support in the community. Managing pain after surgery does take a village!

\section{REFERENCES}

Akbari, M., \& Celik, S. S. (2015, Jul-Aug). The effects of discharge training and counseling on post-discharge problems in patients undergoing coronary artery bypass graft surgery. Iran Journal of Nursing and Midwifery Research, 20(4), 442-449. https://doi.org/10.4103/17359066.161007

Bjornnes, A. K., Moons, P., Parry, M., Halvorsen, S., Tonnessen, T., \& Lie, I. (2019, Nov 11). Experiences of informal caregivers after cardiac surgery: a systematic integrated review of qualitative and quantitative studies. BMJ Open, 9(11), e032751. https://doi.org/10.1136/bmjopen-2019032751

Bjornnes, A. K., Parry, M., Lie, I., Fagerland, M. W., Watt-Watson, J., Rustoen, T., Stubhaug, A., \& Leegaard, M. (2016, Oct). Pain experiences of men and women after cardiac surgery. Journal of Clinical Nursing, 25(19-20), 3058-3068. https://doi.org/10.1111/jocn.13329

Bruehl, S., Olsen, R. B., Tronstad, C., Sevre, K., Burns, J. W., Schirmer, H., Nielsen, C. S., Stubhaug, A., \& Rosseland, L. A. (2018, Jan). Chronic pain-related changes in cardiovascular regulation and impact on comorbid hypertension in a general population: the Tromso study. Pain, 159(1),

119-127. https://doi.org/10.1097/j.pain.000000000 0001070

Chou, R., Gordon, D. B., de Leon-Casasola, O. A., Rosenberg, J. M., Bickler, S., Brennan, T., Carter, T., Cassidy, C. L., Chittenden, E. H., Degenhardt, E., Griffith, S., Manworren, R., McCarberg, B., Montgomery, R., Murphy, J., Perkal, M. F., Suresh, S., Sluka, K., Strassels, S., Thirlby, R., Viscusi, E., Walco, G. A., Warner, L., Weisman, S. J., \& Wu, C. L. (2016, Feb). Management of Postoperative Pain: A Clinical Practice Guideline From: The American Pain Society, the American Society of Regional Anesthesia and Pain Medicine, and the American Society of Anesthesiologists' Committee on Regional Anesthesia, Executive Committee, and Administrative Council. Journal of Pain, 17(2), 131-157. https://doi.org/10.1016/j.jpain.2015.12.0 08

Clarke, H. (2016). Transitional Pain Medicine: novel pharmacological treatments for the management of moderate to severe postsurgical pain. Expert Review of Clinical Pharmacology, 9(3), 345-349. https://doi.org/10.1586/17512433.2016.1 129896

Edwards, R. R., Dworkin, R. H., Sullivan, M. D., Turk, D. C., \& Wasan, A. D. (2016, Sep). The Role of Psychosocial Processes in the 
Development and Maintenance of Chronic Pain. Journal of Pain, 17(9 Suppl), T70-92.

https://doi.org/10.1016/j.jpain.2016.01.0 01

Engelman, D. T., Ben Ali, W., Williams, J. B., Perrault, L. P., Reddy, V. S., Arora, R. C., Roselli, E. E., Khoynezhad, A., Gerdisch, M., Levy, J. H., Lobdell, K., Fletcher, N., Kirsch, M., Nelson, G., Engelman, R. M., Gregory, A. J., \& Boyle, E. M. (2019, Aug 1). Guidelines for Perioperative Care in Cardiac Surgery: Enhanced Recovery After Surgery Society Recommendations. JAMA Surgery, 154(8), 755-766. https://doi.org/10.1001/jamasurg.2019.11 53

Fayaz, A., Ayis, S., Panesar, S. S., Langford, R. M., \& Donaldson, L. J. (2016, Oct). Assessing the relationship between chronic pain and cardiovascular disease: A systematic review and meta-analysis. Scandinavian Journal of Pain, 13, 76-90. https://doi.org/10.1016/j.sjpain.2016.06.0 05

Fredericks, S., \& Yau, T. (2013, Nov). Educational intervention reduces complications and rehospitalizations after heart surgery. Western Journal of Nursing Research, 35(10),

1251-1265. https://doi.org/10.1177/01939459134900 81

Gatchel, R. J., Peng, Y. B., Peters, M. L., Fuchs, P. N., \& Turk, D. C. (2007, Jul). The biopsychosocial approach to chronic pain: scientific advances and future directions. Psychological Bulletin, 133(4), 581-624. https://doi.org/10.1037/00332909.133.4.581

Grondin, F., Bourgault, P., \& Bolduc, N. (2014, Mar). Intervention focused on the patient and family for better postoperative pain relief. Pain Management Nursing, 15(1), 76-86.

https://doi.org/10.1016/j.pmn.2012.06.00 6

Guimaraes-Pereira, L., Reis, P., Abelha, F., Azevedo, L. F., \& Castro-Lopes, J. M. (2017, Oct). Persistent postoperative pain after cardiac surgery: a systematic review with meta-analysis regarding incidence and pain intensity. Pain, 158(10), 18691885.

https://doi.org/10.1097/j.pain.000000000 0000997

HEAL initiative-Pain Management Effectiveness

Research Network (2019). National Institutes of Health. Retrieved November from

https://heal.nih.gov/research/clinicalresearch/pain-management-research

Hirji, S. A., Landino, S., Cote, C., Lee, J., Orhurhu, V., Shah, R. M., McGurk, S., Kaneko, T., Shekar, P., \& Pelletier, M. P. (2019, Feb). Chronic opioid use after coronary bypass surgery. Journal of Cardiac Surgery, 34(2), 67-73. https://doi.org/10.1111/jocs.13981

Interagency Pain Research Coordinating Committee-National Pain Strategy Overview. (2016). National Institutes of Health.

https://www.iprcc.nih.gov/National-PainStrategy/Overview

Katz, J., \& Seltzer, Z. (2009, 5/2009). Transition from acute to chronic postsurgical pain: risk factors and protective factors. Expert. Review Neurotherapy, 9(5), 723-744. https://doi.org/10.1586/ern.09.20 [doi] (Not in File)

Kehlet, H., Edwards, RR, Brennan, T. (2014). Persistent postoperative pain: Pathogenic mechanisms and preventive strategies. In S. Raja, Sommer, C, (Ed.), Pain 2014: Refresher courses (pp. 113-123). International Association for the Study of Pain (IASP) Press.

Lapum, J. L., Fredericks, S., Liu, L., Yau, T. M., Retta, B., Jones, V. M., \& Hume, S. (2016, Jul-Aug). Facilitators and Barriers of Heart Surgery Discharge: Patients' and Nurses' Narrative Accounts. Journal of Cardiovascular Nursing, 31(4), 350-356. https://doi.org/10.1097/JCN.0000000000 000253

Martorella, G., Boitor, M., Berube, M., Fredericks, S., Le May, S., \& Gelinas, C. (2017, Nov 10). Tailored Web-Based Interventions for Pain: Systematic Review and MetaAnalysis. Journal of Medical Internet Resesearch, 19(11), e385. https://doi.org/10.2196/jmir.8826 
Martorella, G., Gelinas, C., \& Purden, M. (2014). Acceptability of a web-based and tailored intervention for the self-management of pain after cardiac surgery: the perception of women and men. JMIR Research Protocols, 3(4), e63. https://doi.org/10.2196/resprot.3175

Martorella, G., Graven, L., Schluck, G., Berube, M., \& Gelinas, C. (2018). Nurses' Perception of a Tailored Web-Based Intervention for the Self-Management of Pain After Cardiac Surgery. SAGE Open Nursing, 4, 1-14. https://doi.org/10.1177/23779608188062 70

Martorella, G., \& McDougall, G. J., Jr. (2021, Feb). Barriers and Facilitators to the Prevention of Chronic Pain in the Subacute Phase After Cardiac Surgery. Pain Management Nursing, 22(1), 28-35. https://doi.org/10.1016/j.pmn.2020.09.00 4

McClintock, A. S., McCarrick, S. M., Garland, E. L., Zeidan, F., \& Zgierska, A. E. (2019, Mar). Brief Mindfulness-Based Interventions for Acute and Chronic Pain: A Systematic Review. Journal of Alternative Complementary Medicine, 25(3), 265-278. https://doi.org/10.1089/acm.2018.0351

Mori, M., Angraal, S., Chaudhry, S. I., Suter, L. G., Geirsson, A., Wallach, J. D., \& Krumholz, H. M. (2019, Nov 5). Characterizing Patient-Centered Postoperative Recovery After Adult Cardiac Surgery: A Systematic Review. Journal of the American Heart Association, 8(21), e013546. https://doi.org/10.1161/JAHA.119.01354 6

Oliveira, C. B., Maher, C. G., Franco, M. R., Kamper, S. J., Williams, C. M., Silva, F. G., \& Pinto, R. Z. (2020, Jun 1). Cooccurrence of Chronic Musculoskeletal Pain and Cardiovascular Diseases: A Systematic Review with Meta-analysis. Pain Medicine, 21(6), 1106-1121. https://doi.org/10.1093/pm/pnz217

Oliver, J. B., Kashef, K., Bader, A. M., \& Correll, D. J. (2016, Nov). A survey of patients' understanding and expectations of persistent postsurgical pain in a preoperative testing center. Journal of Clinical Anesthesia, 34, 494-501. https://doi.org/10.1016/j.jclinane.2016.06 .008

Rahmani, M., Bahraminejad, N., \& Rezaei, M. (2020, Jan-Feb). The Effect of FamilyOriented Educational Intervention on Postoperative Pain after Orthopedic Surgery. Iranian Journal of Nursing Midwifery Research, 25(1), 47-52. https://doi.org/10.4103/ijnmr.IJNMR_127 $-18$

Raja, S. N., Carr, D. B., Cohen, M., Finnerup, N. B., Flor, H., Gibson, S., Keefe, F. J., Mogil, J. S., Ringkamp, M., Sluka, K. A., Song, X. J., Stevens, B., Sullivan, M. D., Tutelman, P. R., Ushida, T., \& Vader, K. (2020, Sep 1). The revised International Association for the Study of Pain definition of pain: concepts, challenges, and compromises. Pain, 161(9), 1976-1982. https://doi.org/10.1097/j.pain.000000000 0001939

Schug, S. A., \& Bruce, J. (2017, Nov). Risk stratification for the development of chronic postsurgical pain. Pain Reports, 2(6), e627. https://doi.org/10.1097/PR9.0000000000 000627

Shaffer, K. M., Tigershtrom, A., Badr, H., Benvengo, S., Hernandez, M., \& Ritterband, L. M. (2020, Mar 4). Dyadic Psychosocial eHealth Interventions: Systematic Scoping Review. Journal of Medical Internet Research, 22(3), e15509. https://doi.org/10.2196/15509

Son, A. Y., Karim, A. S., Fiehler, M., Andrei, A. C., Vassallo, P., Churyla, A., Pham, D. T., McCarthy, P. M., \& Chris Malaisrie, S. (2021, Apr). Outcomes of 3-day discharge after elective cardiac surgery. Journal of Cardiac Surgery, 36(4), 1441-1447. https://doi.org/10.1111/jocs.15404

van der Meij, E., Anema, J. R., Otten, R. H., Huirne, J. A., \& Schaafsma, F. G. (2016). The Effect of Perioperative E-Health Interventions on the Postoperative Course: A Systematic Review of Randomised and NonRandomised Controlled Trials. PLoS One, 11(7), e0158612. 
https://doi.org/10.1371/journal.pone.015 8612

van Hecke, O., Hocking, L. J., Torrance, N., Campbell, A., Padmanabhan, S., Porteous, D. J., Mclntosh, A. M., Burri, A. V., Tanaka, H., Williams, F. M., \& Smith, B. H. (2017). Chronic pain, depression and cardiovascular disease linked through a shared genetic predisposition: Analysis of a family-based cohort and twin study. PLoS One, 12(2), e0170653. https://doi.org/10.1371/journal.pone.017 0653

Virani, S. S., Alonso, A., Aparicio, H. J., Benjamin, E. J., Bittencourt, M. S., Callaway, C. W., Carson, A. P., Chamberlain, A. M., Cheng, S., Delling, F. N., Elkind, M. S. V., Evenson, K. R., Ferguson, J. F., Gupta, D. K., Khan, S. S., Kissela, B. M., Knutson, K. L., Lee, C. D., Lewis, T. T., Liu, J., Loop, M. S., Lutsey, P. L., Ma, J., Mackey, J., Martin, S. S., Matchar, D. B., Mussolino, M. E., Navaneethan, S. D., Perak, A. M., Roth, G. A., Samad, Z., Satou, G. M., Schroeder, E. B., Shah, S. H., Shay, C. M., Stokes, A., VanWagner, L. B., Wang, N. Y., Tsao, C. W., American Heart Association Council on, E., Prevention Statistics, C., \& Stroke Statistics, S. (2021, Feb 23). Heart Disease and Stroke Statistics-2021 Update: A Report From the American Heart Association. Circulation, 143(8), e254-e743. https://doi.org/10.1161/CIR.0000000000 000950

Warren, C., Jaisankar, P., Saneski, E., Tenberg, A., \& Scala, E. (2020, Dec). Understanding
Barriers and Facilitators to Nonpharmacological Pain Management on Adult Inpatient Units. Pain Management Nursing, 21(6), 480-487. https://doi.org/10.1016/j.pmn.2020.06.00 6

Weinrib, A. Z., Azam, M. A., Birnie, K. A., Burns, L. C., Clarke, H., \& Katz, J. (2017, Nov). The psychology of chronic post-surgical pain: new frontiers in risk factor identification, prevention and management. British Journal of Pain, 11(4), 169-177.

https://doi.org/10.1177/20494637177206 36

Yasmeen, I., Krewulak, K. D., Zhang, C., Stelfox, H. T., \& Fiest, K. M. (2020, Nov). The Effect of Caregiver-Facilitated Pain Management Interventions in Hospitalized Patients on Patient, Caregiver, Provider, and Health System Outcomes: A Systematic Review. Journal of Pain Symptom Management, 60(5), 1034-1046 e1047. https://doi.org/10.1016/j.jpainsymman.20 20.06.030

Ziehm, S., Rosendahl, J., Barth, J., Strauss, B. M., Mehnert, A., \& Koranyi, S. (2017, Jul 12). Psychological interventions for acute pain after open heart surgery. Cochrane Database of Systematic Reviews, 7, CD009984.

https://doi.org/10.1002/14651858.CD009 984.pub3 